\title{
Solid-phase extraction-stepwise elution (SPE-SE) procedure for isolation of dissolved organic matter prior to ESI-FT-ICR-MS analysis
}

\author{
Jitao Lv a, Shuzhen Zhang a, b, *, Lei Luo ${ }^{a}$, Dong Cao ${ }^{\text {a }}$ \\ a State Key Laboratory of Environmental Chemistry and Ecotoxicology, Research Center for Eco-Environmental Sciences, Chinese Academy of Sciences, \\ Beijing 100085, China \\ ${ }^{\mathrm{b}}$ University of Chinese Academy of Sciences, Beijing, 100049, China
}

\section{H I G H L I G H T S}

- A novel solid-phase extraction isolation of dissolved organic matter is proposed.

- Compounds are divided into three fractions prior to FT-ICR-MS analysis.

- Molecules identified are 50\% more than those obtained by conventional methods.

\section{A R T I C L E I N F O}

\section{Article history:}

Received 14 July 2016

Received in revised form

2 October 2016

Accepted 31 October 2016

Available online 1 November 2016

\section{Keywords:}

DOM

SPE

ESI-FT-ICR-MS

Stepwise elution

\section{G R A P H I C A L A B S T R A C T}

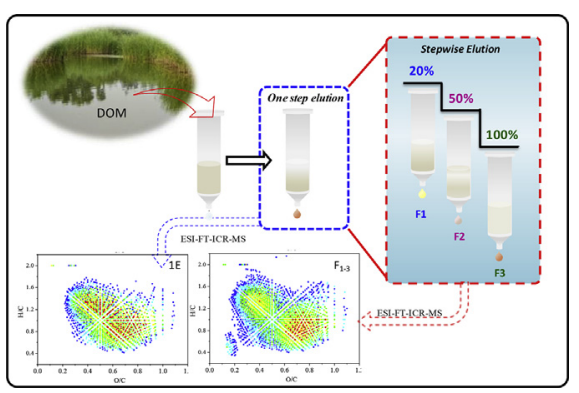

\begin{abstract}
A B S T R A C T
Characterization of dissolved organic matter (DOM) at the molecular level will greatly improve our understanding of its bio-geochemical role in controlling the fate of contaminants in the environment, and Fourier transform ion cyclotron resonance mass spectrometry (FT-ICR-MS) is the most powerful analytical technique for this purpose. Before FT-ICR-MS analysis, isolation, desalination and concentration of DOM are necessary, and solid-phase extraction (SPE) is the most widely applied pretreatment procedure. However, some molecular information is lost using conventional SPE methods. Here, we propose a novel strategy of SPE enrichment using stepwise elution (SPE-SE). Compounds in DOM were divided into three fractions by this SPE-SE procedure according to their polarity and ionization efficiency. The diversity of DOM molecules identified by ESI-FT-ICR-MS using SPE-SE exceeded those using conventional SPE methods by more than $50 \%$. This method is feasible and has the potential to be used as a pretreatment strategy for complex DOM matrixes prior to ESI-FT-ICR-MS analysis, especially for those rich in nitrogenous molecules, carbohydrates, lipids and/or aromatic compounds.
\end{abstract}

๑) 2016 Elsevier B.V. All rights reserved.

\section{Introduction}

DOM is ubiquitous in aquatic environments and plays a

\footnotetext{
* Corresponding author. Research Center for Eco-Environmental Sciences, Chinese Academy of Sciences, P. O. Box 2871, Beijing 100085, China.

E-mail address: szzhang@rcees.ac.cn (S. Zhang).
}

fundamental role in the physical, chemical, and biological processes of almost all contaminants, such as heavy metals, pesticides, persistent organic pollutants, radioactive contaminants, nanoparticles, etc [1-5]. The constituents of DOM are extremely complicated and thus its molecular composition is still largely unknown, which poses a barrier to understanding the molecular mechanism of the interaction between DOM and environmental 
contaminants [6,7]. In the past decades, various techniques including spectroscopic, chromatographic and mass spectrometric methods have been established to investigate the composition and characteristics of DOM. These techniques can provide some bulk information such as elemental composition, apparent molecular weight, and the characteristic functional group distribution of DOM $[6,8,9]$. However, characterization of DOM components at the molecular level remains a challenge due to their highly complex and heterogeneous natures $[10,11]$. Recent progress in Fourier transform ion cyclotron resonance mass spectrometry (FT-ICR-MS) has made it the most promising analytical technique to approach this challenge. Combined with the softer ionization techniques, especially electrospray ionization (ESI), FT-ICR-MS is the only analytical technique that currently can observe a majority of individual DOM components [12-16].

In practice, pretreatment for sample concentration and desalination is typically necessary prior to FT-ICR-MS analysis [17]. Solid phase extraction (SPE) is the most popular method used for this purpose [18-20], and different sorbents such as classical XAD-like resins (Amberlite XAD-8 resin, DAX, etc.), silica-based sorbents $\left(C_{8}\right.$, $\mathrm{C}_{18}$, etc.), and polymer-based sorbents (styrene-divinylbenzene copolymer, PPL) have been tested for their ability to isolate DOM from natural waters $[18,19]$. Among these, PPL sorbent has become a widely accepted medium for the isolation of DOM from natural waters due to its ease of application, high extraction efficiency and the highly representative character of the DOM in isolates [18,21]. In the SPE pretreatment procedures, DOM is first retained by a sorbent, and then eluted in one step using solvents such as methanol. However, recent studies have observed that a great number of compounds in DOM such as highly oxygenated tannin-like molecules [22,23], nitrogenous compounds with high hydrophilic character [23], and fatty-acid-like molecules [24] are preferentially lost during the single-step SPE procedure for a variety of SPE sorbents, such as XAD, $C_{18}$ and PPL [19,22-26]. To solve this problem, combinations of different isolation methods such as dialysis and SPE [24], ultrafiltration and SPE [25] or SPE with a combination of different sorbents $[19,23,26]$ have been attempted recently in order to obtain a more accurate molecular representation of DOM. Nevertheless, the combination of different isolation methods is highly laborious, time-consuming, and hard to optimize and standardize. Therefore, development of a more accessible isolation procedure to obtain a comprehensive molecular representation of DOM is greatly needed [17].

In the present study, we proposed a procedure for the isolation of DOM with PPL by using stepwise elution with a gradient of methanol/water $\left(\mathrm{MeOH} / \mathrm{H}_{2} \mathrm{O}\right)$ ratios prior to ESI-FT-ICR-MS analysis. The results indicated that it is a simple but efficient method for pretreatment of DOM prior to ESI-FT-ICR-MS analysis, and comprehensive molecular characterization of DOM in natural waters was successfully achieved by using the proposed method.

\section{Experimental}

\subsection{Source of dissolved organic matter}

Klasmann peat dissolved organic matter $\left(\mathrm{DOM}_{\mathrm{p}}\right)$ was extracted from fen peat (Klasmann, Germany) in the laboratory. Briefly, the $\mathrm{DOM}_{\mathrm{p}}$ was obtained by end-over-end shaking of $10 \mathrm{~g}$ of peat in $200 \mathrm{~mL}$ ultrapure water for $24 \mathrm{~h}$. The supernatant was obtained by centrifugation at $5000 \mathrm{rpm}$ and filtered through $0.22-\mu \mathrm{m}$ Nylon filters. This extraction process was repeated in triplicate. The final extracted $\mathrm{DOM}_{\mathrm{p}}$ was mixed and kept in the dark at $4{ }^{\circ} \mathrm{C}$ until further analysis. Suwannee River Fulvic Acid (SRFA, 1S101F) was obtained from the International Humic Substance Society (IHSS).

\subsection{Sample preparation}

DOM samples were isolated by the SPE one-step elution (SPE$1 \mathrm{E})$ and SPE stepwise elution (SPE-SE) processes. Sample entrapment and desalination were performed according to Dittmar et al. [18]. Briefly, the SPE cartridges (Varian Bond Elute PPL, $1 \mathrm{~g} / 6 \mathrm{~mL}$ ) were rinsed with two cartridge volumes $(6 \mathrm{~mL})$ of pure methanol (MS grade) and $0.01 \mathrm{M} \mathrm{HCl}$ immediately before use. Fifty $\mathrm{mL}$ of each DOM sample (TOC $\sim 20 \mathrm{mg} \mathrm{L}^{-1}$ ) was acidified with pure $\mathrm{HCl}$ to $\mathrm{pH} 2$ and passed through the SPE cartridges by gravity at a flow rate of about $2 \mathrm{~mL} / \mathrm{min}$. Then, the cartridges were rinsed with two cartridge volumes of $0.01 \mathrm{M} \mathrm{HCl}$ for the complete removal of salts, and then dried under a stream of $\mathrm{N}_{2}$. DOM entrapped by the cartridges was then collected by one-step elution and stepwise elution, respectively. One-step elution, equivalent to the method conventionally used $[18,27]$, was performed by eluting with three cartridge volumes $(18 \mathrm{~mL})$ of pure methanol (MS grade) at a flow rate of $5 \mathrm{~mL} / \mathrm{min}$. Stepwise elution was performed by eluting with $12 \mathrm{~mL}$ (two cartridge volumes) of 20:80 MeOH: $\mathrm{H}_{2} \mathrm{O}$ (v/v, 20\% methanol), $12 \mathrm{~mL}$ 50:50 MeOH: $\mathrm{H}_{2} \mathrm{O}$ (50\% methanol) and $12 \mathrm{~mL} \mathrm{100:0}$ $\mathrm{MeOH}: \mathrm{H}_{2} \mathrm{O}(100 \%$ methanol) at a flow rate of $5 \mathrm{~mL} / \mathrm{min}$, sequentially. The eluted DOM samples were then lyophilized and stored in the dark at $-20^{\circ} \mathrm{C}$. These dried samples were re-dissolved in 50:50 $\mathrm{MeOH}: \mathrm{H}_{2} \mathrm{O}$ for the ESI-FT-ICR-MS analysis. Sample treatment was conducted in triplicate.

\subsection{Negative ionization ESI-FT-ICR-MS analysis}

Ultrahigh resolution mass spectra were acquired using a Bruker SolariX FT-ICR-MS equipped with a 15.0 T superconducting magnet and an ESI ion source as described in our previous study [27]. Samples for FT-ICR-MS analysis were continuously fed into the ESI unit by syringe infusion at a flow rate of $120 \mu \mathrm{L} \mathrm{h}^{-1}$, and each sample was injected twice. The ESI needle voltage was set to $-3.8 \mathrm{kV}$. All the samples were analyzed in negative ionization mode with broadband detection. Ions were accumulated in a hexapole ion trap for $0.1 \mathrm{~s}$ before being introduced into the ICR cell. $4 \mathrm{M}$ words of data were recorded per broadband mass scan. The lower mass limit was set to $m / z=200 \mathrm{Da}$ and the upper mass limit to $m / z=1000 \mathrm{Da}$, respectively. One hundred mass spectra were averaged per sample. The spectra were first externally calibrated using a linear calibration based on sodium formate $(10 \mathrm{mM})$ in $50 \%$ isopropyl alcohol, and then internally calibrated using about 50 molecular formulas with wide mass range in the mass list of normal organic matter reference materials. The mass measurement accuracy for singly charged ions across the $m / z$ range of 200-700 Da was better than $\pm 0.5 \mathrm{ppm}$. Peaks with a signal-to-noise ratio (S/ $\mathrm{N}) \geq 6$ were used to identify $\mathrm{C}_{5-50} \mathrm{H}_{10-100} \mathrm{O}_{0-40} \mathrm{~N}_{0-2}$ molecular formulas using Bruker Data Analysis software based on the requirement that the mass error for a given chemical formula between measured mass and calculated mass was $\leq 0.5 \mathrm{ppm}$, and that the formulas must be a part of a homologous series. Elements $\mathrm{P}$ and $S$ were excluded because of their low detection levels in all the DOM samples. The elemental ratios of $\mathrm{H} / \mathrm{C}<2.2$ and $\mathrm{O} / \mathrm{C}<1.2$ were used as further restrictions for formula calculation. The final identified molecular formulas were obtained based on those present in both of the replicates. The nominal oxidation state of carbon (NOSC) per molecule was estimated from equation (1) assuming that all other elements are in their initial oxidation states $(\mathrm{H}=+1$, $\mathrm{O}=-2, \mathrm{~N}=-3$ and $\mathrm{S}=-2$ ) [28].

$\operatorname{NOSC}=4-[(4 c+h-3 n-2 o-2 s) / c]$

where $\mathrm{c}, \mathrm{h}, \mathrm{n}, \mathrm{o}$, and s refer to the stoichiometric numbers of carbon, hydrogen, nitrogen, oxygen, and sulfur atoms per formula, 
respectively. Here, s equals 0 since $S$ was excluded in the identified molecular formulas.

\section{Results}

\subsection{Molecular characterization of $\mathrm{C}_{c} \mathrm{H}_{h} \mathrm{O}_{o}$ compounds in DOM by ESI-FT-ICR-MS}

Fig. 1A displays the negative-ion ESI-FT-ICR-MS spectra of $\mathrm{DOM}_{\mathrm{p}}$ isolated by SPE-1E and SPE-SE $\left(F_{1}, F_{2}\right.$, and $F_{3}$ refer to DOM fractions isolated by $20 \%, 50 \%$, and $100 \% \mathrm{MeOH}$, respectively). The molecular weight distributions of DOM varied from 200 to $700 \mathrm{Da}$, and the most abundant intensities were distributed in the range of 300-500 Da. Expanded regions of individual nominal mass (Fig. 1B and $C$ ) showed that the intensities of the peaks at low mass defect decreased from $F_{1}$ to $F_{3}$, while the intensities of the peaks at high mass defect increased from $F_{1}$ to $F_{3}$. The low-mass-defect species were indicative of the compounds with high oxygen content and/or low hydrogen content [29]. Fig. 1B shows the scale-expanded views of the mass spectra at an odd mass of $m / z$ 371. There were 10 $\mathrm{C}_{\mathrm{C}} \mathrm{H}_{\mathrm{h}} \mathrm{O}_{\mathrm{o}}$ molecular formulas identified in the SPE-1E spectra at a nominal mass of 371 , and $7,10,12 \mathrm{C}_{\mathrm{C}} \mathrm{H}_{\mathrm{h}} \mathrm{O}_{\mathrm{o}}$ molecular formulas identified in SPE-SE $\left(F_{1}, F_{2}\right.$ and $\left.F_{3}\right)$ spectra (Table $S 1$ ), respectively. All the molecular formulas identified in $F_{1}$ and $F_{2}$ were observed in SPE-1E; however, four molecular formulas with low $\mathrm{O}$ content in $\mathrm{F} 3$ were not evident in SPE-1E (molecular formulas are presented in Fig. 1B and Table S1). Fig. 1C shows the scale-expanded views of mass spectra at an odd mass of $m / z 575$. Eleven $\mathrm{C}_{\mathrm{C}} \mathrm{H}_{\mathrm{h}} \mathrm{O}_{\mathrm{o}}$ molecular formulas were identified in the SPE-1E spectra at a nominal mass of 575 , and 8,7 and $12 \mathrm{C}_{\mathrm{c}} \mathrm{H}_{\mathrm{h}} \mathrm{O}_{\mathrm{o}}$ molecular formulas were identified in
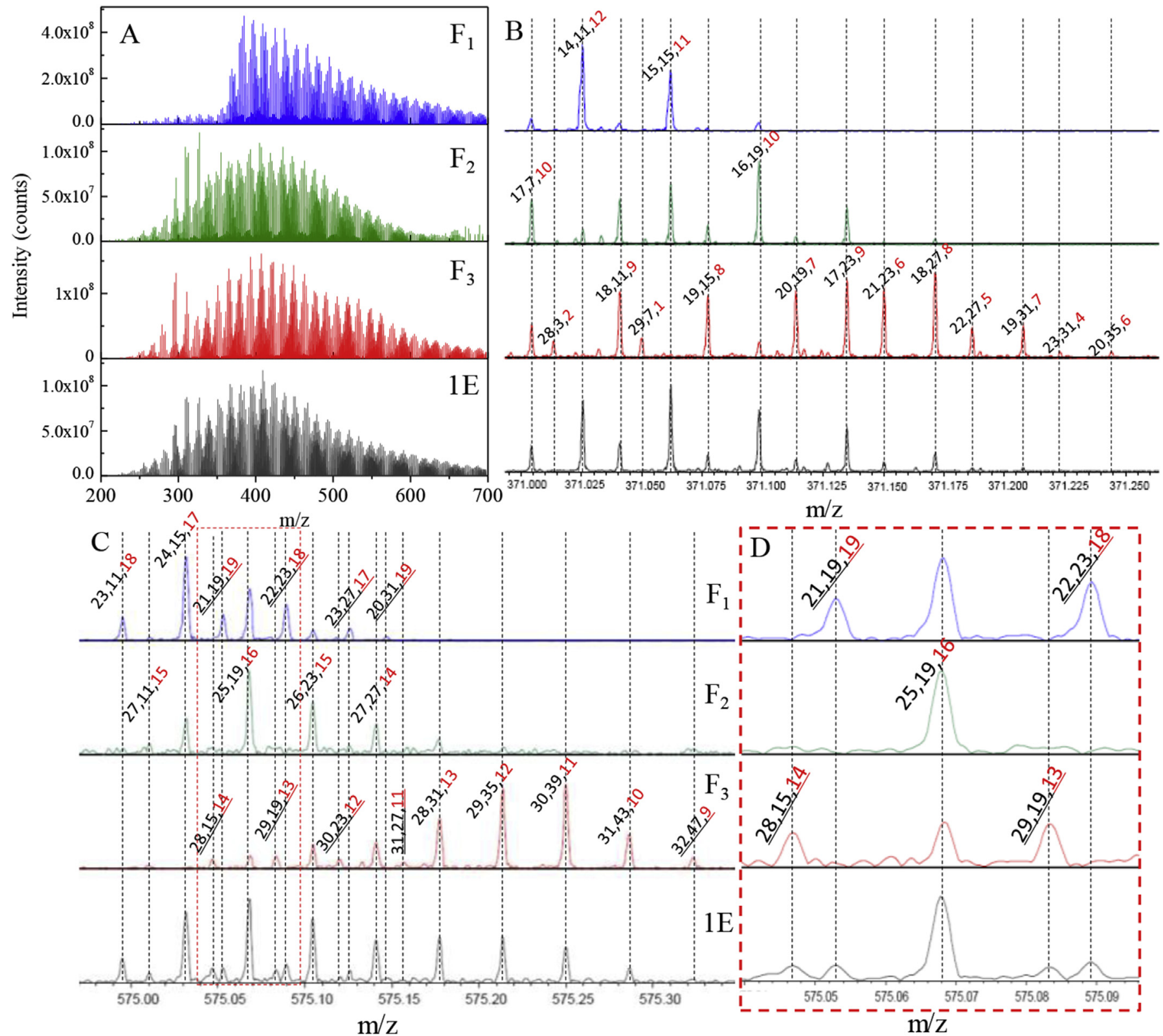

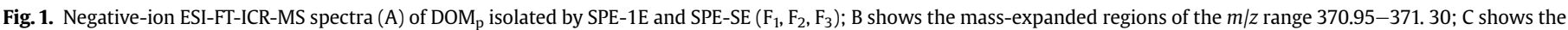

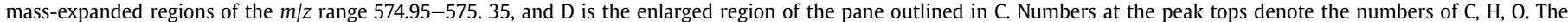

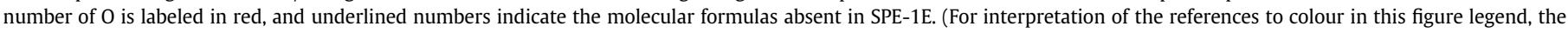
reader is referred to the web version of this article.) 
SPE-SE of $F_{1}, F_{2}$ and $F_{3}$ spectra, respectively. In summary, eight molecular formulas were not observed in SPE-1E (underlined labeled molecular formulas presented in Fig. 1C and Table S1), among which the molecular formulas with the highest $\mathrm{O}$ content (18-19 O) were only observed in $F_{1}$, and 4 molecular formulas with lower $\mathrm{O}$ content (9-14 $\mathrm{O}$ ) were only observed in $\mathrm{F}_{3}$. In particular, it can be seen from the enlarged region of $m / z 575.04-575.10$ (Fig. 1D) that an excellent $m / z$ separation of $F_{1}$ from $F_{3}$, such as $\mathrm{C}_{21} \mathrm{H}_{19} \mathrm{O}_{19}$ (575.052602) from $\mathrm{C}_{28} \mathrm{H}_{15} \mathrm{O}_{14} \quad$ (575.046729) and $\mathrm{C}_{22} \mathrm{H}_{23} \mathrm{O}_{18}$ (575.088988) from $\mathrm{C}_{29} \mathrm{H}_{19} \mathrm{O}_{13}$ (575.083114), was obtained, although there was only a slight mass difference $(0.005874 \mathrm{Da})$ between these molecular formulas. However, overlap was observed between some of the adjacent peaks in the SPE-1E spectra.

In summary, there were 1486,1456 and $2126 \mathrm{C}_{\mathrm{C}} \mathrm{H}_{\mathrm{h}} \mathrm{O}_{\mathrm{o}}$ molecular formulas identified in $F_{1}, F_{2}$ and $F_{3}$ of $D_{p O M}$ isolated by SPE-SE respectively, and a total of $3191 \mathrm{C}_{\mathrm{C}} \mathrm{H}_{\mathrm{h}} \mathrm{O}_{\mathrm{o}}$ molecular formulas (S/ $\mathrm{N} \geq 6$ ) were uniquely identified, which was much larger than the $2061 \mathrm{C}_{\mathrm{C}} \mathrm{H}_{\mathrm{h}} \mathrm{O}_{\mathrm{o}}$ molecular formulas $(\mathrm{S} / \mathrm{N} \geq 6$ ) obtained by SPE-1E (as shown in Table 1). Comparing the $\mathrm{C}_{\mathrm{c}} \mathrm{H}_{\mathrm{h}} \mathrm{O}_{\mathrm{o}}$ molecular formulas obtained, there were 1978 molecular formulas observed in both SPE$1 \mathrm{E}$ and SPE-SE, and 1213 molecular formulas observed only in SPESE. However, only 83 molecular formulas not found in SPE-SE were observed in SPE-1E (Fig. S1, less than $4 \%$ of the total identified molecular formulas in $1 \mathrm{E})$ with weak peak intensity $(\mathrm{S} / \mathrm{N}<32)$. The total number of molecular formulas observed in SPE-SE exceeded the ones observed in SPE-1E by 55\%. Fig. 2 shows the van Krevelen diagrams for the total $\mathrm{C}_{\mathrm{c}} \mathrm{H}_{\mathrm{h}} \mathrm{O}_{\mathrm{o}}$ formulas observed in $\mathrm{DOM}_{\mathrm{p}}$ isolated by SPE-1E and SPE-SE and the formulas only observed in $F_{1-3}$, respectively. In comparison, higher $\mathrm{O} / \mathrm{C}$ compounds were abundant in $\mathrm{F}_{1}$; medial $\mathrm{O} / \mathrm{C}$ and $\mathrm{H} / \mathrm{C}$ compounds were abundant in $\mathrm{F}_{2}$, and low $\mathrm{O} / \mathrm{C}$ compounds were abundant in $\mathrm{F}_{3}$. Molecular formulas obtained only in SPE-SE mainly distributed at the margin of the van Krevelen diagrams, especially in the left (low $\mathrm{O} / \mathrm{C}$ ) and right (high $\mathrm{O} / \mathrm{C}$ ) regions.

To test the reliability of the SPE-SE, standard SRFA obtained from IHSS was further analyzed by negative-ion ESI-FT-ICR-MS using the same pretreatment methods. There were $1704 \mathrm{C}_{\mathrm{c}} \mathrm{H}_{\mathrm{h}} \mathrm{O}_{\mathrm{o}}$ compounds $(\mathrm{S} / \mathrm{N} \geq 6)$ identified using the SPE-1E method, while there were $2536 \mathrm{C}_{\mathrm{C}} \mathrm{H}_{\mathrm{h}} \mathrm{O}_{\mathrm{o}}$ compounds $(\mathrm{S} / \mathrm{N} \geq 6)$ identified using the SPE-SE method, among which $873 \mathrm{C}_{\mathrm{c}} \mathrm{H}_{\mathrm{h}} \mathrm{O}_{\mathrm{o}}$ compounds were identified only in SPE-SE, exceeding the total number of $\mathrm{C}_{\mathrm{C}} \mathrm{H}_{\mathrm{h}} \mathrm{O}_{\mathrm{o}}$ compounds in SPE-1E by $49 \%$. SRFA had fewer $\mathrm{C}_{\mathrm{C}} \mathrm{H}_{\mathrm{h}} \mathrm{O}_{\mathrm{o}}$ compounds identified than DOM extracted from Klasmann peat, especially in the regions of high $\mathrm{H} / \mathrm{C}$ or high $\mathrm{O} / \mathrm{C}$, such as saturated aliphatic, carbohydrate and tannic-like compounds, likely due to the complicated extraction process of SRFA [21]. However, the characters of molecules in different eluted fractions were similar to those of $\mathrm{DOM}_{\mathrm{p}}$ (shown in Fig. S2), with compounds with low $\mathrm{O} / \mathrm{C}$ being dominant in $\mathrm{F}_{1}$ and compounds with high $\mathrm{O} / \mathrm{C}$ dominant in $\mathrm{F}_{3}$. In addition, the

Table 1

Numbers of $\mathrm{C}_{\mathrm{c}} \mathrm{H}_{\mathrm{h}} \mathrm{O}_{\mathrm{o}}$ and $\mathrm{C}_{\mathrm{c}} \mathrm{H}_{\mathrm{h}} \mathrm{O}_{\mathrm{o}} \mathrm{N}_{1-2}$ molecular formulas observed in DOM $\mathrm{P}$ and SRFA isolated by SPE-1E and SPE-SE.

\begin{tabular}{|c|c|c|c|c|c|c|c|}
\hline & \multicolumn{4}{|c|}{ SPE-SE } & \multirow[t]{2}{*}{ SPE-1E } & \multirow{2}{*}{$\frac{\mathrm{F}_{1-3}}{\text { only }}$} & \multirow[t]{2}{*}{$1 \mathrm{E}$ only } \\
\hline & $\mathrm{F}_{1}$ & $\mathrm{~F}_{2}$ & $\mathrm{~F}_{3}$ & $F_{1-3}$ & & & \\
\hline $\mathrm{DOMp}^{\mathrm{b}}$ & 1486 & 1456 & 2126 & 3191 & 2061 & 1213 & 83 \\
\hline DOMp $^{c}$ & 494 & 491 & 296 & 947 & 620 & 463 & 136 \\
\hline SRFA $^{b}$ & 1272 & 1704 & 1818 & 2536 & 1704 & 873 & 41 \\
\hline SRFA $^{C}$ & 289 & 232 & 242 & 545 & 303 & 283 & 42 \\
\hline
\end{tabular}

${ }^{a}$ Data were collected from one representative spectrum of ESI-FT-ICR-MS analysis due to the fact that the errors for the number of identified molecular formulas $(\mathrm{S} / \mathrm{N} \geq 6)$ of replicate samples were $2 \%-5 \%$.

b Represents $\mathrm{C}_{\mathrm{C}} \mathrm{H}_{\mathrm{h}} \mathrm{O}_{\mathrm{o}}$ molecular formulas.

c Represents $\mathrm{C}_{\mathrm{C}} \mathrm{H}_{\mathrm{h}} \mathrm{O}_{\mathrm{o}} \mathrm{N}_{1-2}$ molecular formulas. abundances of the NOSC per $\mathrm{C}_{\mathrm{C}} \mathrm{H}_{\mathrm{h}} \mathrm{O}_{\mathrm{o}}$ formula in different DOM fractions by SPE-1E and SPE-SE $\left(F_{1}, F_{2}\right.$ and $\left.F_{3}\right)$ are shown in Fig. $3 A$ and C. Similar distributions of NOSC for compounds in $\mathrm{DOM}_{\mathrm{p}}$ and SRFA were observed. By using SPE-SE, all compounds in DOM were divided into three groups with different NOSC distributions. Fraction $\mathrm{F}_{1}$ was dominated by compounds with negative NOSC, while Fraction $\mathrm{F}_{3}$ was dominated by compounds with positive NOSC.

\subsection{Molecular characterization of $\mathrm{C}_{c} \mathrm{H}_{h} \mathrm{O}_{0} \mathrm{~N}_{1-2}$ compounds in DOM by ESI-FT-ICR-MS}

Due to the low content of nitrogen in $\mathrm{DOM}_{\mathrm{p}}$ and SRFA (below $1.5 \%)$, only one or two nitrogen atoms per molecules were matched. As a result, the peak intensities and the number of $\mathrm{C}_{\mathrm{C}} \mathrm{H}_{\mathrm{h}} \mathrm{O}_{0} \mathrm{~N}_{1-2}$ compounds were much lower than the corresponding values for $\mathrm{C}_{\mathrm{c}} \mathrm{H}_{\mathrm{h}} \mathrm{O}_{\mathrm{o}}$ compounds. Fig. 4 and Fig. $\mathrm{S} 3$ display the van Krevelen diagrams for all the $\mathrm{C}_{c} \mathrm{H}_{h} \mathrm{O}_{0} \mathrm{~N}_{1-2}$ formulas observed in $\mathrm{DOM}_{\mathrm{p}}$ and SRFA isolated by SPE-1E and SPE-SE and the formulas observed only in $\mathrm{F}_{1-3}$, respectively. In total, 620 and $303 \mathrm{C}_{\mathrm{c}} \mathrm{H}_{\mathrm{h}} \mathrm{O}_{0} \mathrm{~N}_{1-2}$ compounds $(\mathrm{S} / \mathrm{N} \geq 6)$ were identified in $\mathrm{DOM}_{\mathrm{p}}$ and SRFA using the SPE-1E method; while there were 947 and $545 \mathrm{C}_{\mathrm{c}} \mathrm{H}_{\mathrm{h}} \mathrm{O}_{0} \mathrm{~N}_{1-2}$ compounds $(\mathrm{S} / \mathrm{N} \geq 6)$ identified in $\mathrm{DOM}_{\mathrm{p}}$ and SRFA using the SPE-SE method, respectively. Compounds identified only in SPE-SE were 463 and 283 in DOM $\mathrm{p}_{\mathrm{p}}$ and SRFA, exceeding the total $\mathrm{C}_{\mathrm{c}} \mathrm{H}_{\mathrm{h}} \mathrm{O}_{0} \mathrm{~N}_{1-2}$ compounds in SPE- $1 \mathrm{E}$ by $53 \%$ and $80 \%$ (Table 1 ). Fig. 5 shows the massexpanded regions of the $m / z$ range $473.0-474.25$ for $\mathrm{DOM}_{\mathrm{p}}$ isolated by SPE-1E and SPE-SE. Only three $\mathrm{C}_{\mathrm{C}} \mathrm{H}_{\mathrm{h}} \mathrm{O}_{0} \mathrm{~N}_{1-2}$ molecular formulas were identified in the SPE-1E spectra, whereas 8,4 and 3 $\mathrm{C}_{\mathrm{C}} \mathrm{H}_{\mathrm{h}} \mathrm{O}_{0} \mathrm{~N}_{1-2}$ molecular formulas were identified in SPE-SE $\left(\mathrm{F}_{1}, \mathrm{~F}_{2}\right.$ and $F_{3}$ ) spectra, respectively. Five molecular formulas in $F_{1}$ and 3 molecular formulas in $\mathrm{F}_{3}$ were not observed in SPE-1E (underlined labeled molecular formulas presented in Fig. 5 and Table S2). As a whole, the distribution of fractions isolated by SPE-SE was similar to those of $\mathrm{C}_{\mathrm{C}} \mathrm{H}_{\mathrm{h}} \mathrm{O}_{\mathrm{o}}$ (as shown in Fig. 4 and Fig. S3), compounds with low $\mathrm{O} / \mathrm{C}$ being dominant in $\mathrm{F}_{1}$ and compounds with high $\mathrm{O} / \mathrm{C}$ dominant in $\mathrm{F}_{3}$. Furthermore, the abundances of NOSC per $\mathrm{C}_{\mathrm{c}} \mathrm{H}_{\mathrm{h}} \mathrm{O}_{\mathrm{o}} \mathrm{N}_{1-2}$ formula clearly indicated that, similar to the $\mathrm{C}_{\mathrm{C}} \mathrm{H}_{\mathrm{h}} \mathrm{O}_{\mathrm{o}}$ compounds, $\mathrm{C}_{\mathrm{c}} \mathrm{H}_{\mathrm{h}} \mathrm{O}_{0} \mathrm{~N}_{1-2}$ compounds in both DOM $\mathrm{M}$ and SRFA were also divided into three fractions $\left(F_{1}, F_{2}\right.$, and $\left.F_{3}\right)$ by using SPE-SE (Fig. 3C and D).

\section{Discussion}

DOM has been considered to be a supramolecular association composed of thousands of small-molecule components, which are self-assembled by hydrophobic interactions and hydrogen bonds [30]. These small compounds display various physical and chemical properties. FT-ICR-MS is becoming a powerful tool to analyze the molecules of DOM due to its high mass resolution and because preseparation is not required [31,32]. For ESI-FT-ICR-MS analysis, the ionization efficiency of a compound is a very important factor influencing the detection efficiency $[17,33]$. The compounds in DOM are distributed over a wide range of ionization efficiency. Ionization of the low-efficiency compounds will be suppressed with the increase of the high-efficiency compounds [33,34], limiting the detection of compounds with low ionization efficiency at low concentration [24,34]. Conventionally, one-step elution uses an organic solvent such as methanol to elute all the DOM components into one sample $[18,19]$. The present study provided a simple method using stepwise elution by $\mathrm{MeOH} / \mathrm{H}_{2} \mathrm{O}$ with various ratios to divide the compounds in DOM into three fractions with different NOSC, a parameter representing the polarity of compounds in DOM since it is directly related to the $\mathrm{H} / \mathrm{C}$ and $\mathrm{O} / \mathrm{C}$ ratios of a compound [28]. In general, the ionization efficiency of a compound is positively correlated to its polarity. Therefore, the ionization efficiency 

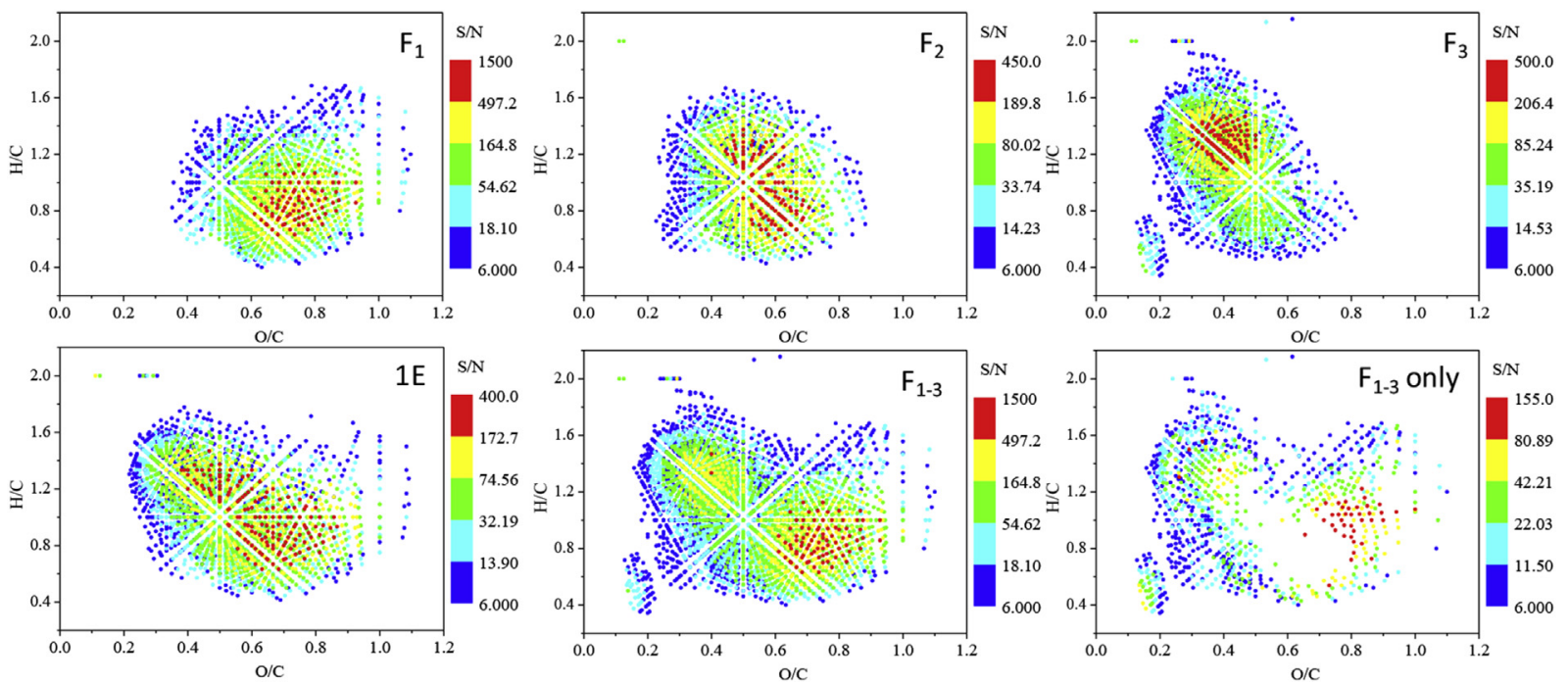

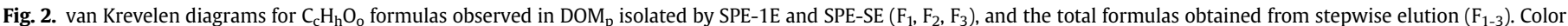
bars represent the $\mathrm{S} / \mathrm{N}$ of peaks. (For interpretation of the references to colour in this figure legend, the reader is referred to the web version of this article.)
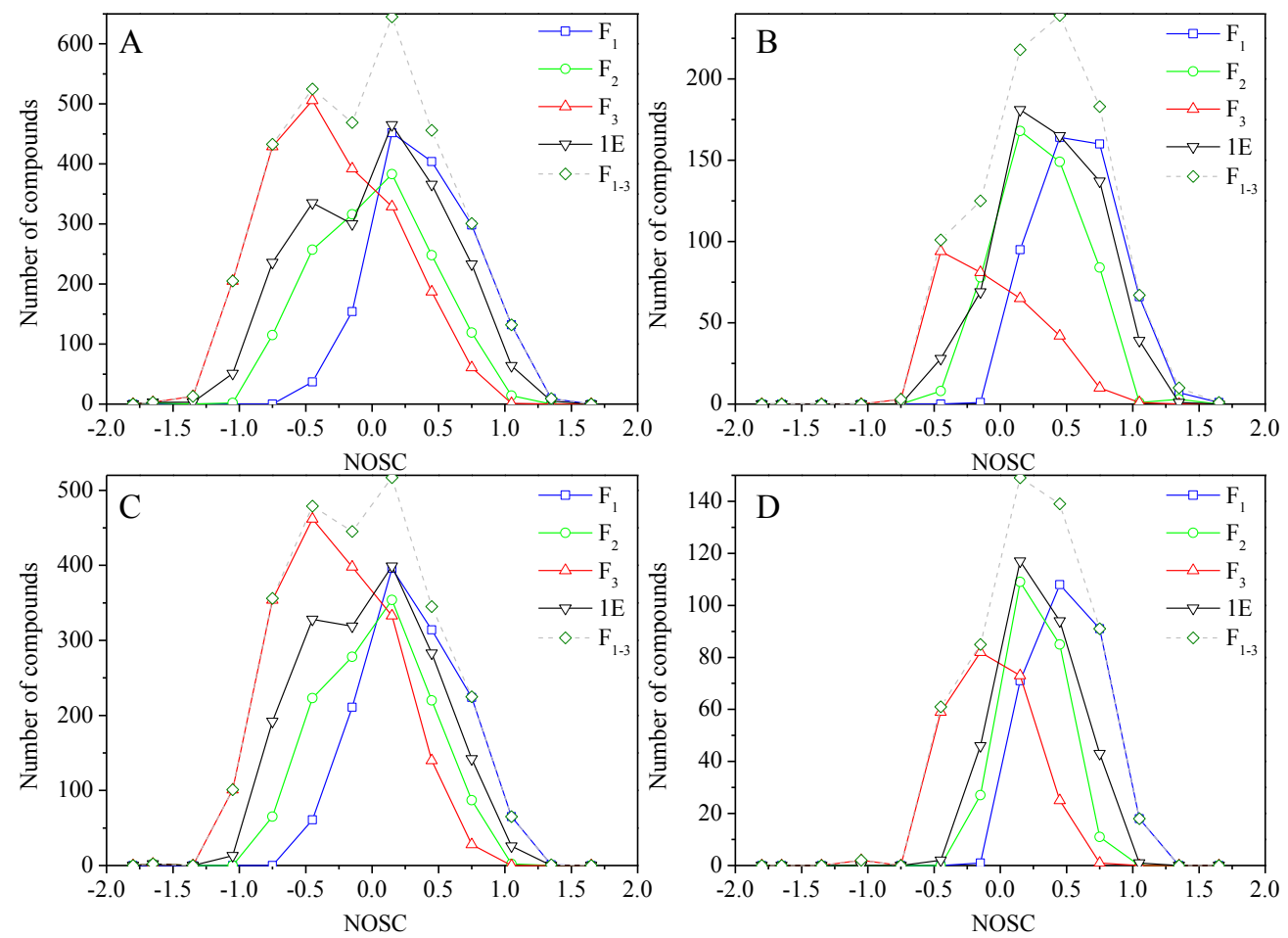

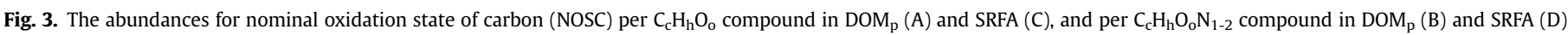
isolated by SPE-1E and SPE-SE $\left(F_{1}, F_{2}, F_{3}\right)$.

of the compounds in DOM divided by stepwise elution can be divided into high $\left(\mathrm{F}_{1}\right)$, medium $\left(\mathrm{F}_{2}\right)$ and low $\left(\mathrm{F}_{3}\right)$ fractions according to their polarity, respectively. The difference in ionization efficiency between compounds in the same isolated fractions also decreased compared to the bulk DOM. This is especially favorable for detection of compounds with low polarity such as the compounds in $\mathrm{F}_{3}$, so that more compounds with low $\mathrm{O} / \mathrm{C}$ were detected in $\mathrm{F}_{3}$, whereas they were absent in SPE-1E, and $F_{1}$ and $F_{2}$ as well. Another plausible mechanism for the high signals of the compounds with low $\mathrm{O} / \mathrm{C}$ is the special enrichment of these compounds in $\mathrm{F}_{3}$ factions by SPE-SE.
On the other hand, the number of identified compounds with high $\mathrm{O} / \mathrm{C}$, especially the carbohydrates, tannin-like $\mathrm{C}_{\mathrm{C}} \mathrm{H}_{\mathrm{h}} \mathrm{O}_{\mathrm{o}}$ compounds and nitrogenous molecules, increased compared with SPE$1 \mathrm{E}$ because they were mainly eluted by the high water content eluting agent $\left(80 \%, \mathrm{~F}_{1}\right.$ in stepwise elution) due to their high hydrophilicity. In general, these very hydrophilic compounds are likely to be lost by nonionic-sorbent-based SPE cartridges such as PPL-, $C_{18^{-}}$, and Amberlite XAD-8 resin [19,22,26]. The weak anionexchange resin diethylaminoethyl (DEAE)-cellulose could extract highly oxygenated compounds in natural water $[19,26]$, but the contents of aliphatic and aromatic compounds were reduced. In 

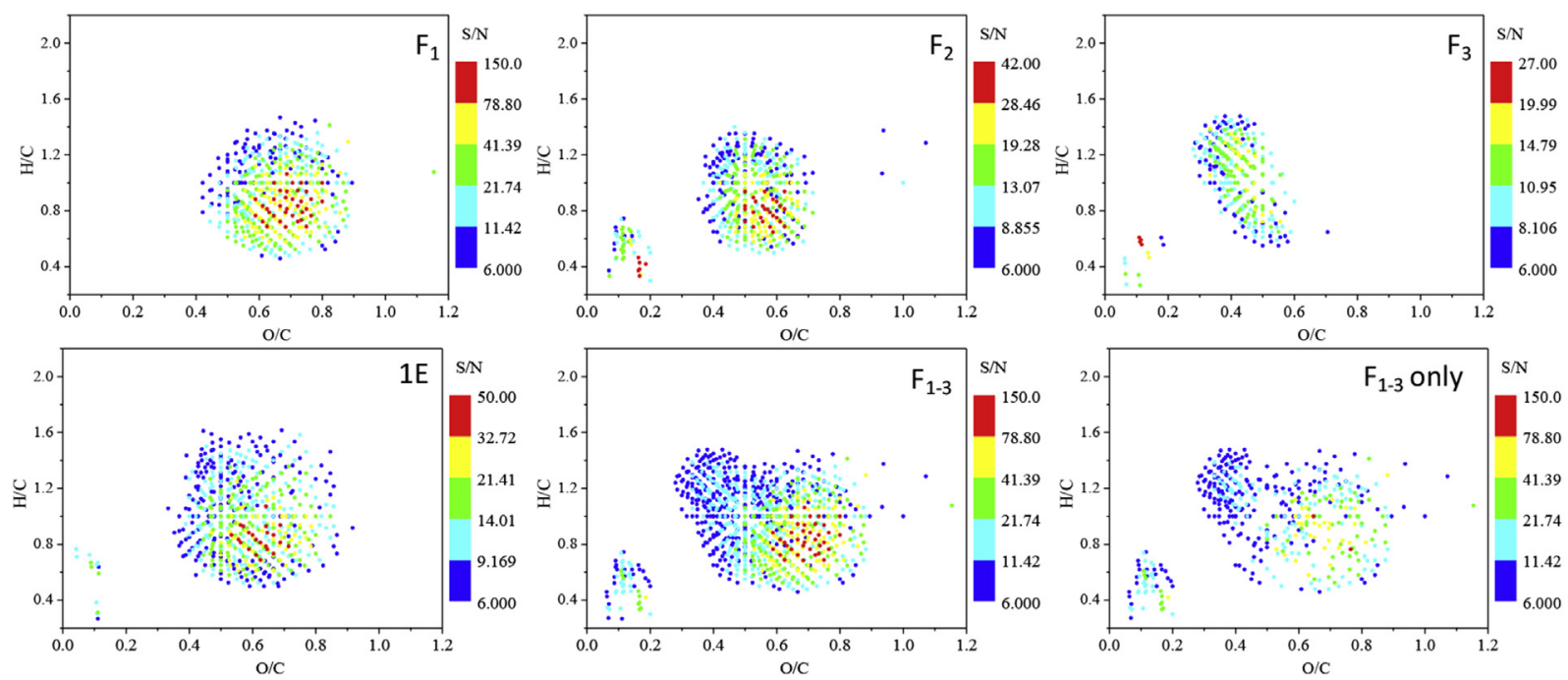

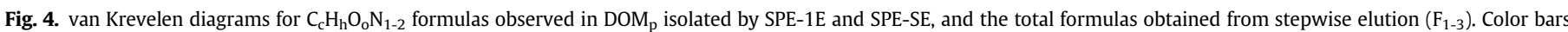
represent the $\mathrm{S} / \mathrm{N}$ of peaks. (For interpretation of the references to colour in this figure legend, the reader is referred to the web version of this article.)

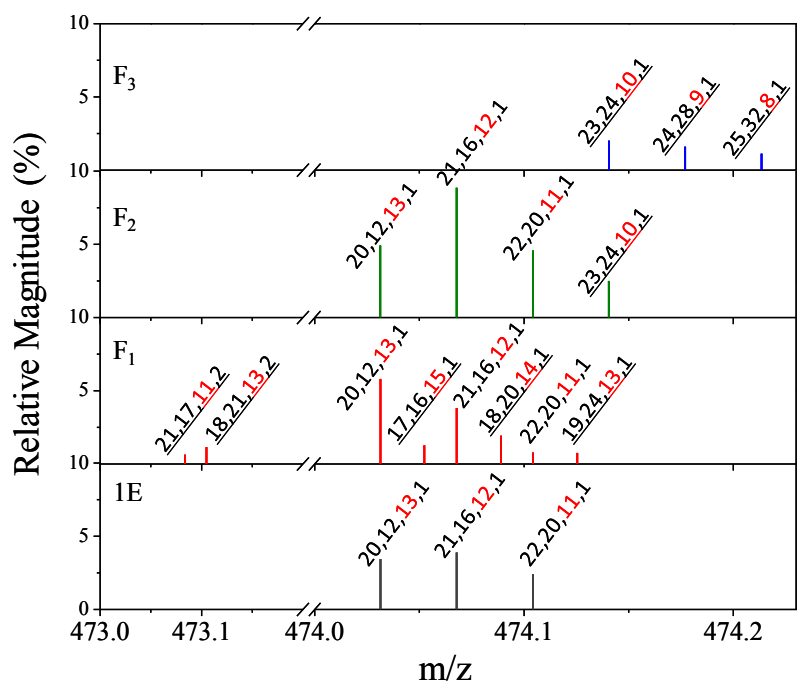

Fig. 5. The mass-expanded regions of the $m / z$ range $473.0-474.25$ for negative-ion ESI-FT-ICR-MS spectra of DOM $\mathrm{p}_{\mathrm{p}}$ isolated by SPE-1E and SPE-SE $\left(\mathrm{F}_{1}, \mathrm{~F}_{2}, \mathrm{~F}_{3}\right)$. Relative magnitudes represent peak intensities normalized to the most intense peak in the spectrum. Numbers at the peak tops denote the numbers of $\mathrm{C}, \mathrm{H}, \mathrm{O}, \mathrm{N}$. The number of $\mathrm{O}$ is labeled in red, and underlined numbers indicate the molecular formulas absent in SPE-1E. (For interpretation of the references to colour in this figure legend, the reader is referred to the web version of this article.)

particular, nitrogenous molecules in DOM are hard to isolate from aqueous samples on hydrophobic stationary phases due to their hydrophilic and zwitterionic characters [23]. Here, by using the SPE-SE procedure, the number of identified nitrogenous molecules $(\mathrm{S} / \mathrm{N} \geq 6)$ detected by ESI-FT-ICR-MS was highly improved compared with the SPE-1E method (total $\mathrm{C}_{\mathrm{C}} \mathrm{H}_{\mathrm{h}} \mathrm{O}_{\mathrm{o}} \mathrm{N}_{1-2}$ compounds in $\mathrm{DOM}_{\mathrm{p}}$ and SRFA increased by $53 \%$ and $80 \%$ ) even though the $\mathrm{N}$ contents of these two DOM were low. The most abundant $\mathrm{C}_{\mathrm{C}} \mathrm{H}_{\mathrm{h}} \mathrm{O}_{\mathrm{O}} \mathrm{N}_{1-2}$ compounds are present in the $\mathrm{F}_{1}$ fractions due to their high hydrophilicity, which is opposite to the $\mathrm{C}_{\mathrm{C}} \mathrm{H}_{\mathrm{h}} \mathrm{O}_{\mathrm{o}}$ compounds. Therefore, the present method may have great potential for use in the characterization of nitrogenous molecules in DOM as well, and further investigations are necessary to provide more evidence by using more kinds of DOM from different sources.

\section{Conclusions}

The present study proposed a simple and efficient strategy for the isolation of DOM by a solid-phase extraction-stepwise elution (SPE-SE) procedure. Using this method, compounds in DOM are divided into three fractions according to their polarity and ionization efficiency. As a result, more low O-containing compounds such as condensed polycyclic aromatics, oxidized black carbon and lipid can be detected by ESI-FT-ICR-MS. Meanwhile, the numbers of identified O-rich compounds with high hydrophilicity, such as carbohydrates and tannic-like compounds, were increased. In particular, it is also an effective approach to fractionation of the highly nitrogenous molecules in DOM. Although it is timeconsuming to some extent, the numbers of identified $\mathrm{CHO}$ and CHON molecules were much improved (over 50\%) by using the proposed novel SPE-SE method compared with the conventional SPE method. Therefore, it is a promising strategy for the isolation and concentration of DOM from complex matrixes prior to ESI-FTICR-MS analysis, especially for those rich in nitrogenous molecules, carbohydrates, lipids and/or aromatic compounds.

\section{Conflict of interest}

The authors declare no competing financial interest.

\section{Acknowledgments}

This work was funded by the 973 Program of China (Grant 2014CB441102), the Strategic Priority Research Program of the Chinese Academy of Sciences (Grant XDB14020202), and the National Natural Science Foundation of China (Projects 21407161, 21321004 and 21537005).

\section{Appendix A. Supplementary data}

Supplementary data related to this article can be found at http:// dx.doi.org/10.1016/j.aca.2016.10.038.

\section{References}

[1] J.P. Hassett, Chemistry-Dissolved natural organic matter as a microreactor, Science 311 (2006) 1723-1724. 
[2] B.H. Gu, J. Chen, Enhanced microbial reduction of $\mathrm{Cr}(\mathrm{VI})$ and $\mathrm{U}(\mathrm{VI})$ by different natural organic matter fractions, Geochim. Cosmochim. Ac 67 (2003) 3575-3582.

[3] C.K. Remucal, The role of indirect photochemical degradation in the environmental fate of pesticides: a review, Environ. Sci-Proc. Imp. 16 (2014) 628-653.

[4] J.F. Leal, V.I. Esteves, E.B.H. Santos, BDE-209: kinetic studies and effect of humic substances on photodegradation in water, Environ. Sci. Technol. 47 (2013) 14010-14017.

[5] G.R. Aiken, H. Hsu-Kim, J.N. Ryan, Influence of dissolved organic matter on the environmental fate of metals, nanoparticles, and colloids, Environ. Sci. Technol. 45 (2011) 3196-3201.

[6] S. Derenne, T.T.N. Tu, Characterizing the molecular structure of organic matter from natural environments: an analytical challenge, CR. Geosci. 346 (2014) 53-63.

[7] M. Filella, Freshwaters: which NOM matters? Environ. Chem. Lett. 7 (2009) $21-35$.

[8] A. Matilainen, E.T. Gjessing, T. Lahtinen, L. Hed, A. Bhatnagar, M. Sillanpaa, An overview of the methods used in the characterisation of natural organic matter (NOM) in relation to drinking water treatment, Chemosphere 83 (2011) 1431-1442.

[9] S. Sandron, A. Rojas, R. Wilson, N.W. Davies, P.R. Haddad, R.A. Shellie P.N. Nesterenko, B.P. Kelleher, B. Paull, Chromatographic methods for the isolation, separation and characterisation of dissolved organic matter, Environ. Sci-Proc. Imp. 17 (2015) 1531-1567.

[10] R. Sutton, G. Sposito, Molecular structure in soil humic substances: the new view, Environ. Sci. Technol. 39 (2005) 9009-9015.

[11] B.P. Koch, T. Dittmar, M. Witt, G. Kattner, Fundamentals of molecular formula assignment to ultrahigh resolution mass data of natural organic matter, Anal. Chem. 79 (2007) 1758-1763.

[12] E.C. Minor, M.M. Swenson, B.M. Mattson, A.R. Oyler, Structural characterization of dissolved organic matter: a review of current techniques for isolation and analysis, Environ. Sci-Proc. Imp. 16 (2014) 2064-2079.

[13] A.C. Stenson, W.M. Landing, A.G. Marshall, W.T. Cooper, Ionization and fragmentation of humic substances in electrospray ionization Fourier transformion cyclotron resonance mass spectrometry, Anal. Chem. 74 (2002) 4397-4409.

[14] M.M. Tfaily, R.K. Chu, N. Tolic, K.M. Roscioli, C.R. Anderton, L. Pasa-Tolic E.W. Robinson, N.J. Hess, Advanced solvent based methods for molecular characterization of soil organic matter by high-resolution mass spectrometry, Anal. Chem. 87 (2015) 5206-5215.

[15] N. Hertkorn, M. Harir, B.P. Koch, B. Michalke, P. Schmitt-Kopplin, High-field NMR spectroscopy and FTICR mass spectrometry: powerful discovery tools for the molecular level characterization of marine dissolved organic matter, Biogeosciences 10 (2013) 1583-1624.

[16] A.M. Kellerman, D.N. Kothawala, T. Dittmar, L.J. Tranvik, Persistence of dissolved organic matter in lakes related to its molecular characteristics, Nat. Geosci. 8 (2015) 454-459.

[17] T. Reemtsma, Determination of molecular formulas of natural organic matter molecules by (ultra-) high-resolution mass spectrometry status and needs, J. Chromatogr. A 1216 (2009) 3687-3701.

[18] T. Dittmar, B. Koch, N. Hertkorn, G. Kattner, A simple and efficient method for the solid-phase extraction of dissolved organic matter (SPE-DOM) from seawater, Limnol. Oceanogr-Meth. 6 (2008) 230-235.

[19] I.V. Perminova, I.V. Dubinenkov, A.S. Kononikhin, A.I. Konstantinov, A.Y. Zherebker, M.A. Andzhushev, V.A. Lebedev, E. Bulygina, R.M. Holmes,
Y.I. Kostyukevich, I.A. Popov, E.N. Nikolaev, Molecular mapping of sorbent selectivities with respect to isolation of Arctic dissolved organic matter as measured by Fourier transform mass spectrometry, Environ. Sci. Technol. 48 (2014) 7461-7468.

[20] H. Waska, A. Koschinsky, M.J.R. Chancho, T. Dittmar, Investigating the potential of solid-phase extraction and Fourier-transform ion cyclotron resonance mass spectrometry (FT-ICR-MS) for the isolation and identification of dissolved metal-organic complexes from natural waters, Mar. Chem. 173 (2015) 78-92.

[21] Y. Li, M. Harir, M. Lucio, B. Kanawati, K. Smirnov, R. Flerus, B.P. Koch, P. Schmitt-Kopplin, N. Hertkorn, Proposed guidelines for solid phase extraction of Suwannee River dissolved organic matter, Anal. Chem. 88 (2016) 6680-6688.

[22] R.L. Sleighter, P.G. Hatcher, Molecular characterization of dissolved organic matter (DOM) along a river to ocean transect of the lower Chesapeake Bay by ultrahigh resolution electrospray ionization Fourier transform ion cyclotron resonance mass spectrometry, Mar. Chem. 110 (2008) 140-152.

[23] T. Reemtsma, A. These, M. Linscheid, J. Leenheer, A. Spitzy, Molecular and structural characterization of dissolved organic matter from the deep ocean by FTICR-MS, including hydrophilic nitrogenous organic molecules, Environ. Sci. Technol. 42 (2008) 1430-1437.

[24] M.M. Tfaily, S. Hodgkins, D.C. Podgorski, J.P. Chanton, W.T. Cooper, Comparison of dialysis and solid-phase extraction for isolation and concentration of dissolved organic matter prior to Fourier transform ion cyclotron resonance mass spectrometry, Anal. Bioanal. Chem. 404 (2012) 447-457.

[25] J.P. Simjouwa, E.C. Minor, K. Mopper, Isolation and characterization of estuarine dissolved organic matter: comparison of ultrafiltration and C18 solidphase extraction techniques, Mar. Chem. 96 (2005) 219-235.

[26] P.L. Brezonik, P.R. Bloom, R.L. Sleighter, R.M. Cory, A.R. Khwaja, P.G. Hatcher, Chemical differences of aquatic humic substances extracted by XAD-8 and DEAE-cellulose, J. Environ. Chem. Eng. 3 (2015) 2982-2990.

[27] J.T. Lv, S.Z. Zhang, S.S. Wang, L. Luo, D. Cao, P. Christie, Molecular-scale investigation with ESI-FT-ICR-MS on fractionation of dissolved organic matter induced by adsorption on iron oxyhydroxides, Environ. Sci. Technol. 50 (2016) $2328-2336$.

[28] T. Riedel, H. Biester, T. Dittmar, Molecular fractionation of dissolved organic matter with metal salts, Environ. Sci. Technol. 46 (2012) 4419-4426.

[29] S. Kim, R.W. Kramer, P.G. Hatcher, Graphical method for analysis of ultrahighresolution broadband mass spectra of natural organic matter, the van Krevelen diagram, Anal. Chem. 75 (2003) 5336-5344.

[30] A. Piccolo, The supramolecular structure of humic substances, Soil Sci. 166 (2001) 810-832.

[31] M. Witt, J. Fuchser, B.P. Koch, Fragmentation studies of fulvic acids using collision induced dissociation Fourier transform ion cyclotron resonance mass spectrometry, Anal. Chem. 81 (2009) 2688-2694.

[32] R.L. Sleighter, P.G. Hatcher, The application of electrospray ionization coupled to ultrahigh resolution mass spectrometry for the molecular characterization of natural organic matter, J. Mass Spectrom. 42 (2007) 559-574.

[33] K. Tang, J.S. Page, R.D. Smith, Charge competition and the linear dynamic range of detection in electrospray ionization mass spectrometry, J. Am. Soc. Mass Spectrom. 15 (2004) 1416-1423.

[34] T. Ohno, R.L. Sleighter, P.G. Hatcher, Comparative study of organic matter chemical characterization using negative and positive mode electrospray ionization ultrahigh-resolution mass spectrometry, Anal. Bioanal. Chem. 408 (2016) 2497-2504. 